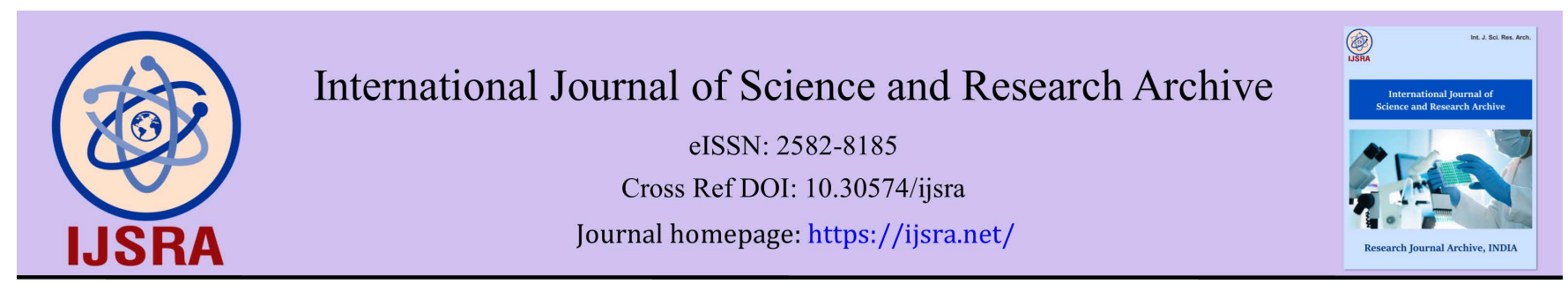

(RESEARCH ARTICLE)

\title{
Medical professionalism among medical students: A multifaceted evaluation
}

\author{
Joy EwennTan ${ }^{1,}{ }^{*}$, Aedin Collins ${ }^{1}$, Rosalinde Tilley ${ }^{2}$ and Manasvi Upadhyaya ${ }^{3}$ \\ ${ }^{1}$ Evelina London Children Hospital, Guy's, United Kingdom. \\ ${ }^{2}$ Undergraduate Medical Education, St Thomas' NHS Foundation Trust, United Kingdom. \\ ${ }^{3}$ Clinical Academic Group, Evelina London Children Hospital, Guy's, United Kingdom.
}

International Journal of Science and Research Archive, 2021, 02(02), 237-244

Publication history: Received on 27 April 2021; revised on 14 June 2021; accepted on 17 June 2021

Article DOI: https://doi.org/10.30574/ijsra.2021.2.2.0082

\begin{abstract}
Background: Professionalism is one of the five key attributes that the General Medical Council has focused on the guideline of Good Medical Practice. The primary aim of this study is to evaluate how the attributes of professionalism among medical students are perceived by themselves (SG) and patients, parents, carers, junior doctors, nurses, consultants and other allied health professionals (NSG). The secondary aim of this study is to evaluate methods of assessment for professionalism.
\end{abstract}

Methods: This study was carried out for a period of 8 weeks. This was a multifaceted evaluation gathering opinions from SG and NSG. All participants filled-in a questionnaire, using a 5-point Likert score scale satisfaction.

Results: In total, we had 185 participants: 88 (SG), and 97 (NSG). The mean score of medical professionalism rated by SG was 3.87 and NSG was 3.95. The top two attributes that scored the highest scores by SG were respectfulness and confidentiality. NSG were confidentiality and appearance. The two attributes that had the lowest score in both groups were attendance and punctuality. One-to-one feedback was the most favorable choice of assessment method among both groups.

Conclusion: The level of professionalism among medical students in this study was observed to be positive. There was no significant difference between both groups. Professionalism is a crucial requirement for all medical doctors. It is all educator's responsibility from all educators to instill medical professionalism from the moment medical school begins.

Keywords: Medical students; Professionalism; Attendance; Punctuality; Confidentiality

\section{Background}

University is a time for learning, personal experimentation and discovery. Many college students are still within the period of their adolescence, a time where a young person establishes their own identity, by gaining independence from parents, experimentation and questioning authority [1]. Other priority of university students includes achievement, hedonism, self-direction, and stimulation [2]. University life for medical students is versatile, with high expectations placed upon them.

The definition of a profession is any work that needs specialized training or a particular skill, often one that is respected because it involves a high level of education. ${ }^{3}$ Professionalism is the combination of all the qualities within trained and skilled people [3].

\footnotetext{
* Corresponding author: Joy EwennTan

Evelina London Children Hospital, Guy's, United Kingdom

Copyright (@ 2021 Author(s) retain the copyright of this article. This article is published under the terms of the Creative Commons Attribution Liscense 4.0.
} 
Professionalism is one of the five key attributes that the General Medical Council (GMC) has focused on in the guideline of Good Medical Practice. The other key attributes being, knowledge skills and performance, safety and quality, communication, maintaining trust, partnership and teamwork [4].

Defining professionalism is not as straight forward as it seems. Medical professionalism has been described as a doctor being able to put the interest of the patient before himself [5]. Sir James Spence once expressed that professionalism is "the essential unit of medical practice is that moment in the intimacy of the consulting room when a patient who is ill or believes himself to be ill, confides in a doctor whom he trusts. This is a consultation, and all else in medicine derives from it." [6].

In the past, professionalism relied on learning the tricks of the trade from role models. At present, medical professionalism is advancing from self- governance and self-interest to accountability, teamwork and shared responsibility [5]. Calman described the 'key morals' expected of professional doctors. These values include a high standard of ethics, continuing professional development, ability to work in a team with scholarship qualities [7]. Medical Professionalism has been gaining global attention due to adverse patient outcomes.

In 2016, a report of medical practitioners revealed that $44 \%$ of respondents felt doctors were less compassionate compared to 20 years ago. 38\% thought that the main issues were the organisational structure and work pressure. $40 \%$ of doctors felt that there were doctors that were undermining respect and preventing effective collaboration. $60 \%$ of doctors were afraid that supervisors or direct line managers do not support their concerns [8].

These unprofessional behaviours from colleagues can lead to potentially preventable adverse events, errors and impact on safety and quality [9]. In a British Medical Association report, medical students felt their attitude and behaviour were more often under the microscope in comparison with other undergraduate courses students. There is a heightened level of concern about why they faced greater scrutiny and constraints. Questions had also arisen about what comprised professional and unprofessional behaviours [10].

Professionalism is a journey that entails attention from the moment a medical student enters medical school until the day of retirement $[11,12]$. The core values and attributes of professionalism need to be emphasised and delivered continuously throughout the undergraduate and postgraduate medical programme [13].

\section{Aim}

The primary aims of this study

- to evaluate how the attributes of professionalism among medical students are perceived by themselves (SG)

- to evaluate how the non-student group, including: patients, parents, carers, junior doctors, nurses, consultants and other allied health professionals (NSG) evaluate the attributes of professionalism among medical students are perceived by

- to identify the differences of opinion between SG and NSG

- to identify the attributes of professionalism that requires attention

The secondary aims of this study

- to ascertain the assessment methods of professionalism

- to assess the opinion of attendance and punctuality among SG

\section{Methods}

\subsection{Ethics}

This anonymized study was registered and approved by Guys and St Thomas' NHS Foundation Trust.

\subsection{Study Design}

This study was a prospective study carried out for a period of 8 weeks from December 2019 to February 2020. This was a multifaceted evaluation gathering opinions from various respondents, including patients, parents, careers, junior doctors, nurses, consultants, allied health professionals and medical students. The respondents were divided into two groups: medical student (SG) and others (NSG). 
All participants evaluated professionalism among medical students by filling in a questionnaire. This questionnaire contained various attributes of professionalism among medical students by using a 5 Likert score scale satisfaction. A score of 5 was most satisfactory and a score of 1 was least satisfactory. The attributes that were measured include: honesty, punctuality, attendance, appearance, compassionate, responsibility, respectfulness, commitment, confidentiality and communication. The list of attributes of professionalism were incorporated from the guidance of Good Medical Practice, as per the General Medical Council [3]. Both groups also evaluated on medical students' attendance and assessment methods for medical professionalism among medical students. For the SG group, they had additional questions about their views on punctuality, attendance taking and consequences of suboptimal attendance.

\subsection{Inclusion criteria}

All medical students from Kings College London from year 1 to year 5, parents/carers and patients, consultants, junior doctors, nurses and allied health professionals who gave consent and were staff or registered patients of Guys and St Thomas' NHS Foundation Trust.

\subsection{Exclusion criteria}

All medical students from Kings College London from year 1 to year 5, parents/carers and patients, consultants, junior doctors, nurses and allied health professionals who did not give consent.

\subsection{Data collection and analysis}

All data were collected via a paper questionnaire or electronic questionnaire. Data collected were saved on Microsoft Excel (registered trademark) and exported to Statistical Package for the Social Sciences (SPSS) computer software for data analysis.

\section{Results}

In total, we had 185 respondents in this study: 88 were SG, and 97 were NSG.

\subsection{Evaluation of medical professionalism among medical students from SG}

The mean score of medical professionalism rated by SG was 3.87. The top two attributes that scored the highest scores were respectfulness (4.41) and confidentiality (4.30). The two attributes that had the lowest score in this group were attendance (3.08) and punctuality (3.21). There is a consistent downward trend of average score from year 1(4.25) to year 5 (3.5). This can be seen in the figure 1 below.

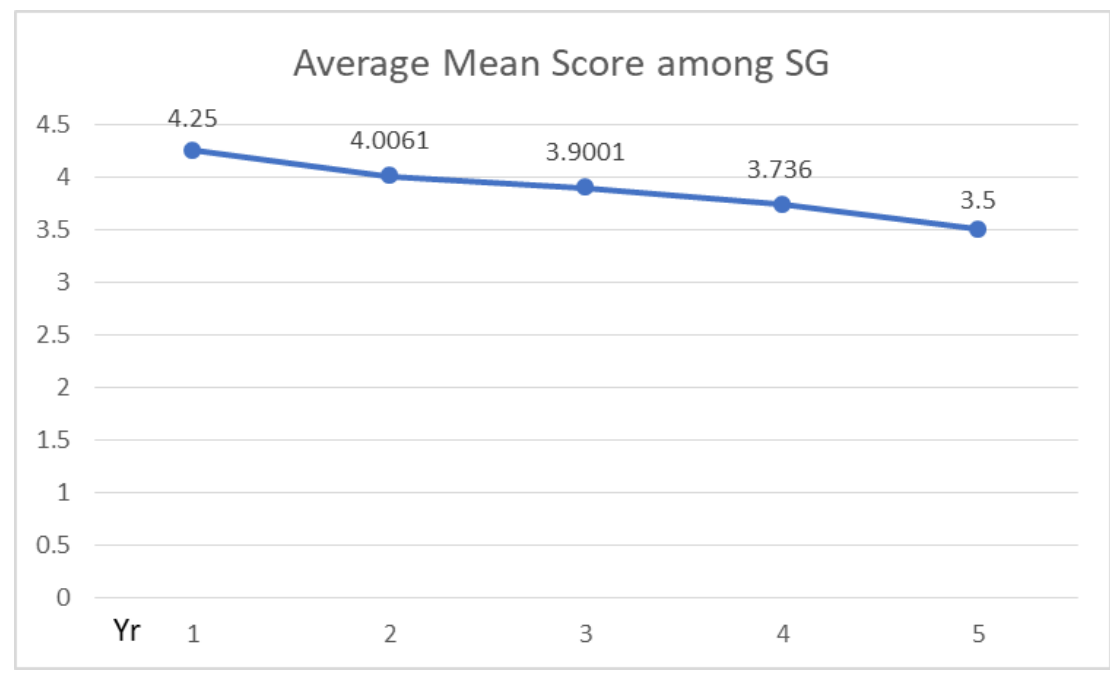

Figure 1 Average evaluation score of medical professionalism among medical student from SG (Axis Y represent the score 0-5 and Axis X is represents year 1-5)

\subsection{Evaluation of medical professionalism among medical students from NSG}

The mean score of medical professionalism rated by NSG was 3.95. The two attributes of professionalism that scored the highest were confidentiality (4.54), and appearance (4.23). The two attributes that scored the lowest were also 
punctuality (3.39) and attendance (3.29). Among the NSG, parent's patients and carers scored medical students' professionalism the highest, with a mean score of 4.56. Meanwhile, clinicians rated medical professionalism among medical student the lowest, with a mean score of 3.68 .

\subsection{The differences of opinion between SG and NSG}

Respectfulness is one of the attributes of professionalism that has the highest disparity in scoring by the two groups: SG (4.41), NSG (4.04) with a p-value of 0.004. The attribute that has the least disparity is compassionate, giving a mean score of 4.09 from SG, 4.03 from non-SG and a p-value of 0.686. An independent t-test was conducted, and it showed overall there were no statistically significant differences between the two groups. This can be illustrated in Table 1 below.

\subsection{Attributes required attention}

The two main attributes that required more attention are attendance and punctuality. They were the two attributes that were scored consistently low in both groups: SG and NSG. This can be seen in Table 1. below.

Table 1 Descriptive analysis of professionalism among SG and non-SG

\begin{tabular}{|c|c|c|c|c|c|}
\hline & Group & $\mathbf{N}$ & Mean & Std. Deviation & Std. Error Mean \\
\hline \multirow{2}{*}{ Honesty } & non- SG & 87 & 4.069 & 0.92502 & 0.09917 \\
\hline & SG & 86 & 3.814 & 1.05732 & 0.11401 \\
\hline \multirow{2}{*}{ Punctuality } & non- SG & 83 & 3.3855 & 1.11346 & 0.12222 \\
\hline & SG & 85 & 3.2118 & 1.07009 & 0.11607 \\
\hline \multirow{2}{*}{ Confidential } & non- SG & 67 & 4.5373 & 0.55945 & 0.06835 \\
\hline & SG & 86 & 4.3023 & 1.0183 & 0.10981 \\
\hline \multirow{2}{*}{ Responsibility } & non- SG & 88 & 3.625 & 1.0429 & 0.11117 \\
\hline & SG & 85 & 3.8471 & 1.12869 & 0.12242 \\
\hline \multirow{2}{*}{ Respectful } & non- SG & 95 & 4.0421 & 0.90994 & 0.09336 \\
\hline & SG & 86 & 4.4186 & 0.84666 & 0.0913 \\
\hline \multirow{2}{*}{ Compassionate } & non- SG & 93 & 4.0323 & 0.87789 & 0.09103 \\
\hline & SG & 86 & 4.093 & 1.12331 & 0.12113 \\
\hline \multirow{2}{*}{ Communication } & non- SG & 94 & 3.9043 & 0.84331 & 0.08698 \\
\hline & SG & 87 & 4.2184 & 0.89476 & 0.09593 \\
\hline \multirow{2}{*}{ Attendance } & non- SG & 84 & 3.2976 & 1.2102 & 0.13204 \\
\hline & SG & 87 & 3.0805 & 1.10199 & 0.11815 \\
\hline \multirow{2}{*}{ Appearance } & non- SG & 95 & 4.2316 & 0.69117 & 0.07091 \\
\hline & SG & 87 & 4.0345 & 1.06146 & 0.1138 \\
\hline \multirow{2}{*}{ Commitment } & non- SG & 82 & 3.6585 & 1.00884 & 0.11141 \\
\hline & SG & 86 & 3.7326 & 1.01082 & 0.109 \\
\hline
\end{tabular}

\subsection{Assessment methods for medical professionalism among medical students: Views from SG and NSG}

One to one feedback was the most favorable choice of assessment method among the SG group (49\%) and the NSG group (31\%). Eight per cent of SG opted for no assessment and commented that professionalism should not be assessed but should be cultivated with role models. Results above can are illustrated in Figure 2. 


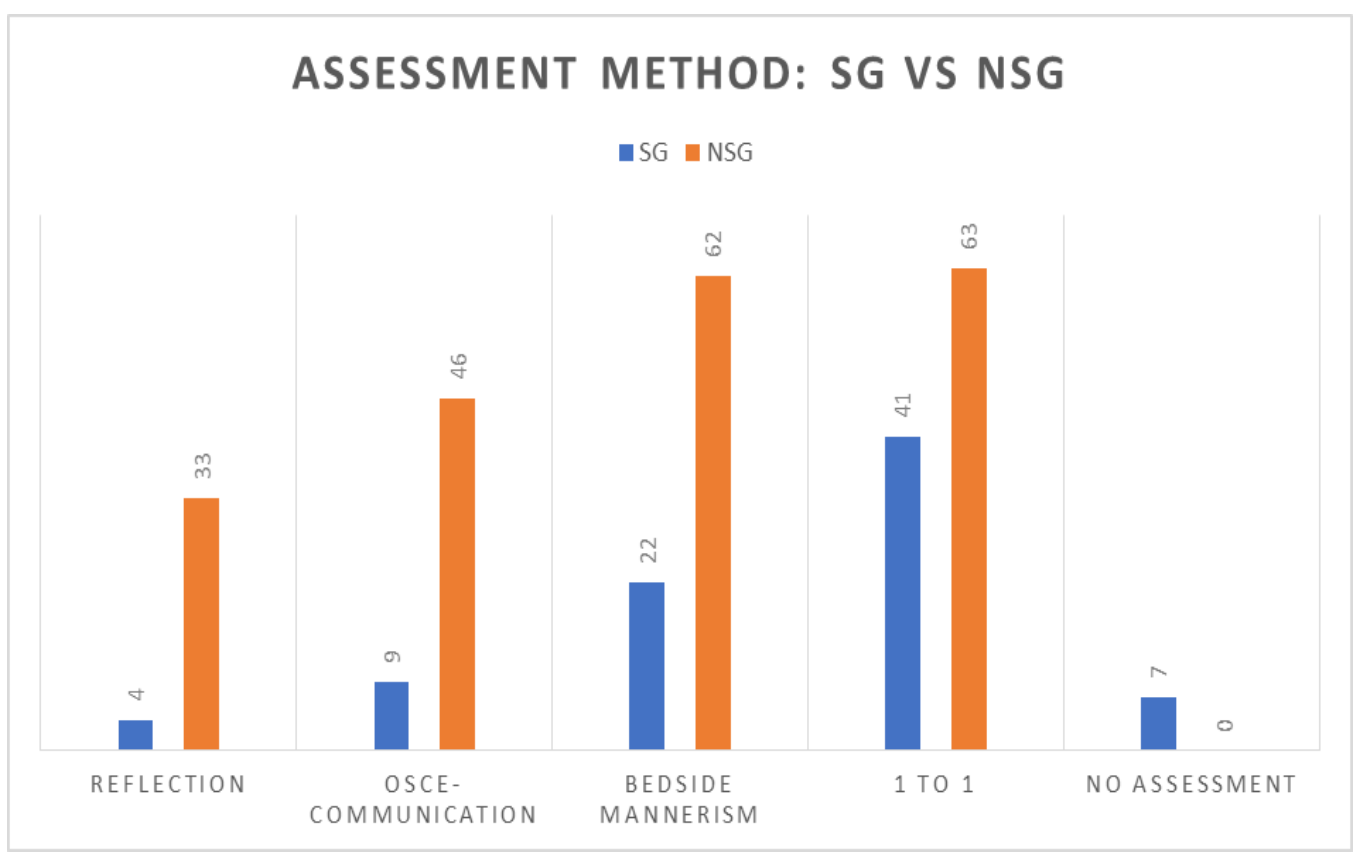

Figure 2 Preferable assessment methods for medical professionalism: SG vs NSG- Axis X representing assessment methods and Axis Y represents the rate voted by NSG and SG.

\subsection{SG and NSG views on attendance}

41 respondents from SG (47 \%) and 45 respondent from NSG (47\%) were in agreement that attendance is 'very important'. 69 respondent from SG (78\%) and 70 respondent from NSG (78\%) agreed that minimum attendance required of a medical student should be above $80 \%$.

\subsection{Views on punctuality and attendance taking among SG}

$77 \%$ of the SG claimed they were on time for scheduled learning activities. The most common reason for being late was a transportation issue. $76 \%$ of them will notify relevant parties if they are late. Even though $78 \%$ of SG agreed that minimum acceptable attendance was $80 \%$, only over $55 \%$ of SG agreed that attendance should be taken for each learning activity. Moreover, $86 \%$ of the SG agreed that action should be taken based on reason if there is suboptimal of attendance.

\section{Discussion}

Overall, our study showed no statistically significant differences between SG's and NSG's view on medical professionalism. A study done at Shahid Beheshti University of Medical Sciences and affiliated hospital in 2016 showed that the knowledge of medical professionalism among medical students and physicians showed no statistical difference [14]. Both SG and NSG groups scored confidentiality as the highest attribute. This suggests that confidentiality is well covered and emphasised in Ethical Module within the undergraduate medical curriculum.

Punctuality and attendance were the two attributes that scored the lowest by SG (3.21 \& 3.08) and NSG (3.39 \& 3.29). Attendance has been a cause of concern in some universities, both non-clinical and clinical placements [15]. This suggests that attendance is a common problem. Although studies have shown that regular attendance correlates with higher academic performance [16-20]. only 47\% of SG and NSG group support that attendance is 'very important' as part of the undergraduate medical programme.

Despite having $78 \%$ of SG agreeing that the minimum acceptable attendance in medical school is $80 \%$, only $55 \%$ of SG agreed that attendance should be taken regularly. This is a dichotomy which supports the finding in a British Medical Association report, stating that medical students felt they were closely monitored, faced greater scrutiny and constraints in comparison with other undergraduate courses [11].

$77 \%$ of SG claimed they were on time, and $76 \%$ of SG would inform the relevant department if they were late. The most common reason for being late was due to transportation. Although medical students are aware that punctuality is essential, however, they do not appreciate that timekeeping is a critical part of the medical profession. 
Respectfulness was one of the attributes of professionalism that had the highest mean score among SG; however, it also had the highest disparity in scores by the two groups: SG (4.41), NSG (4.04) with a p-value of 0.004 . This mismatch of opinions might be secondary to the difference of generation, culture and background [21]. This is an important area for medical educators to be more aware and understanding while training medical students.

It is interesting to note that $8 \%$ of SG suggested that professionalism should not be assessed but needed to be cultivated with a role model. Medical training has always been adapting to the apprenticeship model. However, it has been highlighted by Benbassat that we have to be cautious using role model alone as medical students picking up' positive values' from role models can be subjective and selective [22].

From the result, there was a consistent downward trend of mean score from year 1 to Year 5. As medical students advance from non-clinical to clinical years, more is required of them professionally and academically. This increased more self-reflection about their performance as they progress each year.

Previous study suggested that professionalism issues were often brought forward from pre-clinical years to clinical years [23]. Inappropriate professionalism during the undergraduate period was more at risk of medical professionalism issues in their medical career [24]. Hence it is crucial to have high moral characters developed from the outset of medical school.

In King's College London School of Medicine, there is a medical students' professionalism policy in place, helping the medical school to monitor medical students' behavior. This ensures they meet the standard that was laid out by the General Medical Council. Moreover, it also enables educators to guide medical students requiring their support [25].

\section{Strengths and limitations}

To our knowledge, this is the first multifaceted study evaluating professionalism among medical students and comparing them with patients, parents, careers, junior doctors, nurses, consultants and other allied health professionals. This study was an anonymous study enabling each participant to express their opinion freely.

Our study has a huge sample with a relatively similar sample size of participants in both groups. There is a minimum amount of missing data. From our result, the standard deviation and standard error are small. This suggests that the results of this study were reliable.

This study is a single center study, which might skew the outcome. Since this is the first multifaceted study, hence there is a paucity of literature to support the findings.

This study highlights that punctuality and attendance need more attention to educating medical students. However, there is a limitation in exploring the reason for absentees in this study.

This study also did not include sex, age, ethnicity and education/ work level as part of the measurable variables. However, this could be explored in future study.

\section{Future studies}

In the future, a longitudinal study can be designed to evaluate professionalism from undergraduate to a postgraduate level enabling us to have a more in-depth insight into the trend of medical professionalism from medical student to junior doctor level. This model could also be adapted for other allied health professionals.

Although General Medical Council has included medical professionalism as part of Good Medical Practise, it will be useful to allow medical students themselves to define medical professionalism enabling us to improve medical educators' teaching and medical students' training.

\section{Conclusion}

The level of professionalism among medical students in this study was observed to be positive. There was no significant difference between SG and NSG respondents. Confidentiality was the strongest scoring attributes. However, punctuality and attendance among medical students are the two professionalism attributes requiring more attention from medical educators. 
Professionalism is a crucial requirement for all medical doctors. It is vital to focus on medical professionalism from an early stage. Since the pandemic period, there is a paradigm shift in teaching and learning process. Most learning activities are made available online, and there will be reduced face to face and clinical experience. The apprenticeship model has a limited role in their training. Hence, it is a journey that entails responsibility from all educators to instill medical professionalism from the moment a medical student enters medical school.

\section{Compliance with ethical standards}

\section{Acknowledgments}

JET made contributions to the design of study and analysis. JET is the main author of this paper. JET drafted and revised the manuscript. JET has approved the submitted version.

AC made contributions to the design of the study. AC was involved in data collection. AC drafted the manuscript. AC has approved the submitted version.

RT made contributions to the conception of this study. RT revised and approved the submitted version.

MU made contributions to the design of study and analysis. MU is also the main author of this paper. MU substantively revised the manuscript. MU has approved the submitted version.

\section{Disclosure of conflict of interest}

The authors declare that they have no competing interests.

\section{Statement of ethical approval}

This anonymized study was registered and approved by Guys and St Thomas' NHS Foundation Trust.

\section{Statement of informed consent}

Informed consent was obtained from participants before data collection. All methods were performed in accordance with the relevant guidelines and regulations (Declaration of Helsinki).

\section{Availability of data and materials}

The datasets used and/or analyzed during the current study are available from the corresponding author on reasonable request.

\section{References}

[1] Christie D, Viner R. Adolescent development. BMJ. 2005; 330: 301-4.

[2] Ryckman RM, Houston DM. Value priorities in American and British female and male university students. The Journal of Social Psychology. 2003; 143(1): 127-138.

[3] Cambridge International Dictionary of English. Cambridge: Cambridge University Press. 1995.

[4] General Medical Council, Medical Schools Council. Achieving good medical practice: guidance for medical students. 2016.

[5] Altirkawi K. Teaching professionalism in medicine: what, why and how?. Sudan J Paediatr. 2014; 14(1): 31-38.

[6] Court D. Sir James Spence. Arch Dis Child 1975; 50: 85-89.

[7] Calman K. The profession of medicine. BMJ. 1994; 309: 1140-1143.

[8] Medical professional matters. Report and recommendation. Dec 2016.

[9] Rosenstein AH, O'Daniel M. A survey of the impact of disruptive behaviors and communication defects on patient safety. Jt Comm J Qual Patient Saf. 2008; 34(8): 464-471.

[10] Bagg W, Clark K. Professionalism: medical students, future practice and all of us. Intern Med J. 2017; 47: 133-134. 
[11] As a medical student, am I always on duty? British medical association. May 2020.

[12] Bagg W, Clark K. Professionalism: medical students, future practice and all of us. Intern Med J. 2017; 47: $133-134$.

[13] Braunack-Mayer AJ, Gillam LH, Vance EF, Gillett GR, Kerridge IH, McPhee J, et al. and the Association of Teachers of Ethics and Law in Australian and New Zealand Medical Schools (ATEAM). An ethics core curriculum for Australasian medical schools. Med J Aust 2001; 175: 205-10.

[14] Seif-Farshad M, Bazmi S, Amiri F, Fattahi F, Kiani M. Knowledge of medical professionalism in medical students and physicians at Shahid Beheshti University of Medical Sciences and affiliated hospitals-Iran. Medicine (Baltimore). 2016; 95(45): e5380.

[15] Nevins EJ, Moori PL, Alexander L, Richards B, Bleasdale V, Sharma AK. Could attendance at medical school be improved? A prospective study of medical education at the University of Liverpool: study of attendance at a UK medical school. MedEdPublish. 2016.

[16] Romer D. Do students go to class? Should they? J Econ Perspect. 1993; 7: 167-74.

[17] Von Blerkon ML. Class attendance in undergraduate course. J Psychol. 1992; 123: 487-94.

[18] Gunn KP. A Correlation between attendance and grades in a first year psychology class. Can Psychol. 1993; 34: 202.

[19] Park KH, Kerr PM. A determinant of academic performance: A multinomial logit approach. J Econ Educ. 1990; 21: 101-11.

[20] Nyamapfene A. Does class attendance still matter? Engg Educ. 2010; 5: 1-9.

[21] Chandratilake M, McAleer S, Gibson J. Cultural similarities and differences in medical professionalism: a multiregion study. Med Educ. 2012; 46: 257-266.

[22] Benbassat J. Role modeling in medical education: the importance of a reflective imitation. Acad Med. 2014; 89(4): 550-554.

[23] Esin Kulac, Mekin Sezik, Halil Asci, Duygu K. Doguc. Medical students' participation in and perception of unprofessional behaviors: comparison of preclinical and clinical phases. Advances in Physiology Education 2013; 37(4): 298-302.

[24] Kebede S, Gebremeskel B, Yekoye A, Menlkalew Z, Asrat M, Medhanyie AA. Medical professionalism: perspectives of medical students and residents at Ayder Comprehensive and Specialized Hospital, Mekelle, Ethiopia - a crosssectional study. Adv Med Educ Pract. 2018; 9: 611-616.

[25] https://www.kcl.ac.uk/lsm/research/divisions/hscr/study/undergradops/kumec/teachers/kcl-medicalstudent-professionalism.pdf 